\title{
Inductrack Demonstration Model
}

\author{
R. F. Post
}

February 3, 1998

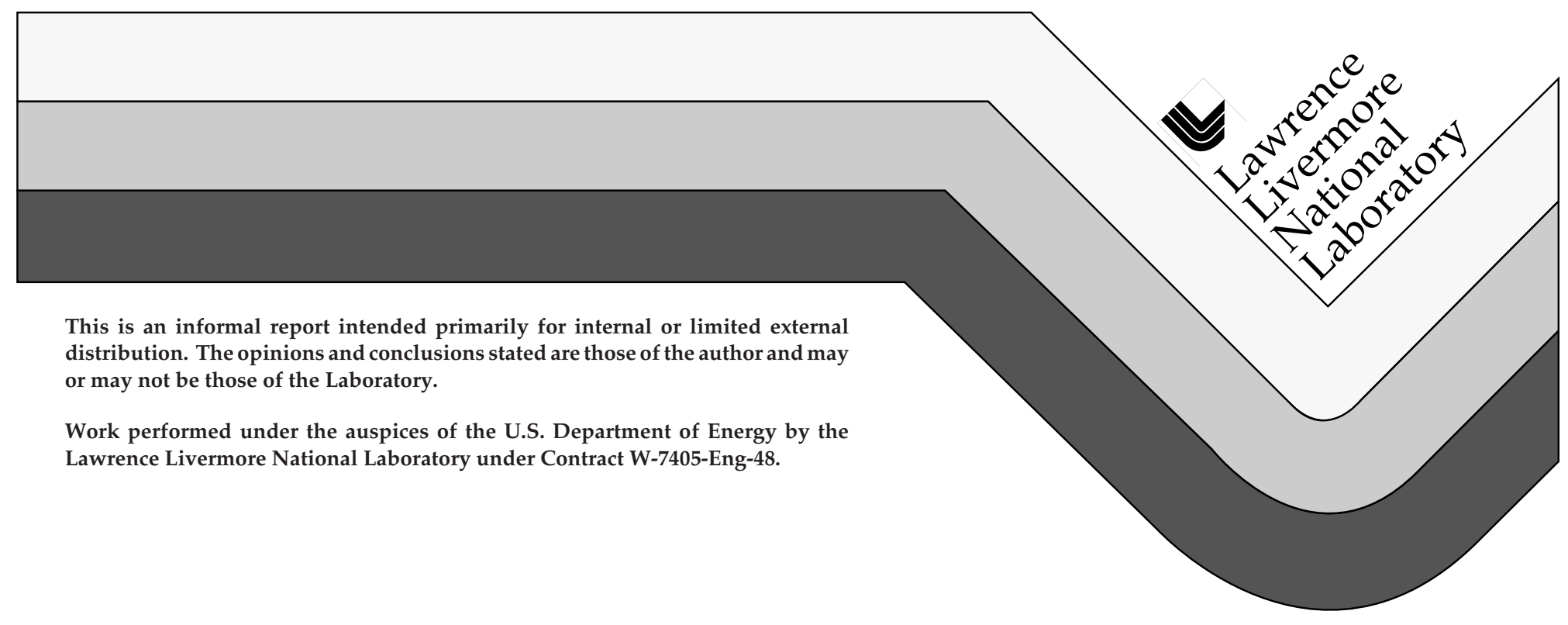




\section{DISCLAIMER}

This document was prepared as an account of work sponsored by an agency of the United States Government. Neither the United States Government nor the University of California nor any of their employees, makes any warranty, express or implied, or assumes any legal liability or responsibility for the accuracy, completeness, or usefulness of any information, apparatus, product, or process disclosed, or represents that its use would not infringe privately owned rights. Reference herein to any specific commercial product, process, or service by trade name, trademark, manufacturer, or otherwise, does not necessarily constitute or imply its endorsement, recommendation, or favoring by the United States Government or the University of California. The views and opinions of authors expressed herein do not necessarily state or reflect those of the United States Government or the University of California, and shall not be used for advertising or product endorsement purposes.

This report has been reproduced directly from the best available copy.

Available to DOE and DOE contractors from the Office of Scientific and Technical Information

P.O. Box 62, Oak Ridge, TN 37831

Prices available from (615) 576-8401, FTS 626-8401

Available to the public from the

National Technical Information Service

U.S. Department of Commerce 5285 Port Royal Rd.,

Springfield, VA 22161 


\title{
Inductrack Demonstration Model
}

\author{
R. F. Post \\ Lawrence Livermore National Laboratory
}

\begin{abstract}
A small-scale model track of a new type of magnetic levitation system (dubbed the "Inductrack" system), and a passively magnetically levitated cart, has been designed, constructed and operated. The track consists of a close-packed array of rectangular levitation coils, 15 centimeters in width transversely and 20 meters in length. The array of coils is inductively loaded above and below its lower horizontal section with ferrite tiles. Paralleling the levitation coils on each side are aluminum-channel rails on which ride auxiliary wheels attached to the cart. The cart has, on its lower surface and on its sides, fore and aft, special arrays ("Halbach arrays") of permanent magnet bars that produce a strong periodic magnetic field below the cart. This magnetic field, when the cart is in motion, induces repelling currents in the Inductrack coils, levitating it and centering it transversely. When mechanically launched (with a pulley-and-weight system) at speeds substantially above a "transition speed" of about 2 meters per second, the cart levitated and flew stably down the track, settling to rest on its wheels near the end of the track. In the last phase of the program an electromagnetic launching section consisting of another array of coils, connected to pulse-driver circuits, was added at the beginning of the track. Aided by an initial launch (from stretched "bungee" cords), this electromagnetic launching system was operated successfully, resulting again in levitation and subsequent stable flight of the cart.
\end{abstract}

\section{(I) Introduction: The Inductrack Concept}

The Inductrack concept is a passive magnetic levitation system for moving objects that employs special arrays of permanent magnets in the moving object. The magnetic field from these arrays induces currents in the "track" that, by interacting with the magnetic field, produce strong lifting forces. By contrast with other magnetic levitation systems, no superconducting magnet coils or servo control circuits are required and the ratio of lifting force to drag force is much higher than magnetic levitation systems that rely on eddy currents induced in conducting surfaces. 
The theory of operation of the Inductrack passive magnetic levitation system is described in another report [1]. The Inductrack system is composed of a "track" comprised of a close-packed array of inductively loaded coils. In the model described here these coils have a rectangular cross-section, as seen in Figure 1, which is a drawing of one of these coils. The moving car to be levitated above it has on its lower surface two "Halbach arrays" [2] composed of bars of permanent-magnetic material $(\mathrm{NbFeB}$ in the present model). These arrays provide the levitating force. The cart also carries four other, smaller, Halbach arrays located at its sides, fore and aft, and below the plane of the levitating array. These side arrays provide a centering action for transverse motion of the cart. A photograph of the cart is shown in Figure 2. The photograph shows how the Halbach arrays are formed by capturing magnet blocks in aluminum tubes with square cross-sections.

In moving over the levitation coils of the Inductrack, the periodic magnetic field produced by the Halbach arrays on the cart induces currents in the levitation coils. As the theory [1] shows, at low speeds these currents will be in phase with the rate of change of the flux and will lead mainly to a drag force that increases with speed, but is accompanied with little lifting force. However, as the speed increases the phase of the current will lag that of the induced voltage by an angle approaching 90 degrees, at which point the lifting force will be a maximum, and the drag force will be greatly reduced, now varying inversely with speed. The relationship between the lift and the drag over the speed range beginning with zero speed is given by the simple equation:

$$
\frac{\text { Lift }}{\text { Drag }}=\omega \mathrm{L} / \mathrm{R}
$$

Here L (hy) is the inductance (self + mutual) of each of the Inductrack coils, and $\mathrm{R}$ (ohms) is its resistance. The angular frequency, $\omega$ (radians/sec.) is the frequency of the varying magnetic field produced by the moving Halbach arrays. This frequency is therefore equal to $2 \pi \mathrm{v} / \lambda$, where $\mathrm{v}$ (meters/sec.) is the speed of the cart and $\lambda$ is the spatial wavelength of the Halbach arrays. The "transition speed," $v_{t}$, the speed where the lift and drag become equal, and the lift has approached one-half of its asymptotic maximum value, is defined through the equality 


$$
\omega \mathrm{L} / \mathrm{R}=1.0, \quad \text { i.e., } \quad \mathrm{v}_{\mathrm{t}}=(\lambda / 2 \pi)(\mathrm{R} / \mathrm{L}) \quad \mathrm{m} . / \mathrm{sec} .
$$

Since the quantity R/L generally decreases upon scale-up of the size of the Inductrack coil array, small-scale models typically require a higher launching speed than would a full-size system. As will be later calculated, the transition speed for the model that was built is about 2 meters/sec., $(7 \mathrm{~km} / \mathrm{hr})$ to be contrasted with a transition speed of order $1.5 \mathrm{~km} / \mathrm{hr} \quad(0.4$ meters $/ \mathrm{sec}$.) that might be typical of a full-scale system. In this respect, therefore, the construction of a small model carries with it a more difficult requirement (higher launching speed) than would larger systems.

In brief review of the theory of the levitating force that is produced at speeds that are high compared to the transition speeds the limiting value of this force per unit area is given by the equation:

$$
\frac{\mathrm{F}_{\max }}{\mathrm{A}}=\frac{\mathrm{B}_{0}^{2}}{\mu_{0}} \exp \left[-\mathrm{k}\left(2 \mathrm{y}+\Delta_{\mathrm{c}}\right)\right] \quad \text { Newtons } / \mathrm{m}^{2}
$$

Here the quantity $\mathrm{B}_{0}$ (Tesla), defined in an equation below, is the peak value of the magnetic field at the lower surface of the Halbach array, $y(m$.$) is the distance from that surface to the upper$ surface of the Inductrack coil array, and $\Delta_{c}(\mathrm{~m}$.$) is the thickness in$ the vertical direction of the conductor bundle. The quantity $\mathrm{k}\left(\mathrm{m}^{-1}\right)$ is equal to $2 \pi / \lambda$, where $\lambda(\mathrm{m}$.) is the wavelength of the Halbach array. The constant $\mu_{0}$ is equal to $4 \pi \times 10^{-7}$ henrys/meter, the permeability of free space in SI units.

In terms of the remanent magnetic field of the permanentmagnet material, the value of $\mathrm{B}_{0}$, as calculated by Halbach [2], is given by the equation:

$$
\mathrm{B}_{0}=\mathrm{B}_{\mathrm{r}}[1-\exp (-\mathrm{kd})] \frac{\sin (\pi / \mathrm{M})}{\pi / \mathrm{M}} \quad \text { Tesla }
$$

Here $\mathrm{d}(\mathrm{m}$.$) is the thickness in the vertical direction of the$ Halbach array, and $\mathrm{M}$ is equal to the number of magnet elements per wavelength ( $\mathrm{M}=4$ in the model as constructed). A "magnet element" as here defined corresponds to a sub-group in the array, consisting of one or more actual bars, within which the direction of magnetization 
is the same. In the case of square magnet bars, with a single bar per sub-group, the equation takes on the value:

$$
\mathrm{B}_{0}=(0.713) \mathrm{B}_{\mathrm{r}} \quad \text { Tesla }
$$

For standard-grade NdFeB magnet material, $\mathrm{B}_{\mathrm{r}}=1.23$ Tesla, so that $\mathrm{B}_{0}=0.877$ Tesla. Inserting this value into equation (3) there results

$$
\frac{\mathrm{F}_{\max }}{\mathrm{A}}=6 \times 10^{5} \exp \left[-\mathrm{k}\left(2 \mathrm{y}+\Delta_{\mathrm{c}}\right)\right] \quad \text { Newtons } / \mathrm{m}^{2}
$$

In this case for small separations (ky $<<1)$, and small conductor thickness $\left(\mathrm{k} \Delta_{\mathrm{c}} \ll 1\right)$, the limiting levitating force is seen to approach 60 metric tonnes $/ \mathrm{m}^{2}$.

How close it is possible to approach the limiting levitation force depends on the design of the Inductrack coils and on the amount of extra inductive loading that is used to augment the intrinsic inductance of the coils (i.e, taking into account both self- and mutualinductance effects). Adding inductive loading leads to lowering the transition speed and to increasing the lift/drag ratio at high speeds. When these effects are taken into consideration the magnitude of the levitating force is reduced, leading to the following expression for the ratio of the available levitating force to its limiting value:

$$
\frac{\mathrm{F}_{\mathrm{y}}}{\mathrm{F}_{\max }}=\frac{\mathrm{w}}{\mathrm{P}_{\mathrm{c}}}\left[\frac{\mathrm{L}_{\mathrm{d}}}{\mathrm{L}_{\mathrm{L}}+\mathrm{L}_{\mathrm{d}}}\right]
$$

Here $\mathrm{w}$ (m.) is the transverse width of the Halbach array, $\mathrm{P}_{\mathrm{c}}(\mathrm{m}$.$) is$ the perimeter of the coil, $\mathrm{L}_{\mathrm{d}}$ (hy) - called the "distributed inductance," and defined below - is the self-inductance of a coil, as augmented by mutual-inductance coupling to the adjacent coils of the track, and $\mathrm{L}_{\mathrm{L}}$ (hy) is the extra inductive loading that may be added (in the case of the model, through the use of ferrite tiles). The total inductance, $\mathrm{L}$, is then equal to the sum of these two terms, i.e., $\mathrm{L}$ $=\mathrm{L}_{\mathrm{L}}+\mathrm{L}_{\mathrm{d}}$

As calculated by Ryutov [1], the value of $L_{d}$ is given by the relationship: 


$$
\mathrm{L}_{\mathrm{d}}=\frac{\mu_{0} \mathrm{P}_{\mathrm{c}}}{2 \mathrm{kd}_{\mathrm{c}}} \quad \mathrm{hy}
$$

Here $d_{c}(m$.$) is the separation distance between the midplanes of$ adjacent coils, which for close-packed coils is just equal to their axial thickness. Equation (8) applies to the "one-turn-equivalent" coil that would be represented by a one-turn coil carrying a uniformly distributed current and having the same conductor cross-section and perimeter as the multi-turn litz-wire coil actually used in the experiment. As can be seen from the scaling laws for the $L / R$ ratio of such coils, these two coils, i.e., the "one-turn-equivalent" and the actual coil, have the same geometry and the same value of $L / R$, thus would behave identically in an Inductrack.

For the specific case of inductive loading by ferrite tiles another calculation made by Ryutov [3] gives the following result for the term in equation (7) involving the ratio of inductances:

$$
\left[\frac{\mathrm{L}_{\mathrm{d}}}{\mathrm{L}_{\mathrm{L}}+\mathrm{L}_{\mathrm{d}}}\right]=\frac{1}{1+\frac{\mathrm{h}}{\mathrm{P}_{\mathrm{c}}}(\mathrm{Q}-1)}
$$

Here the quantity $\mathrm{h}(\mathrm{m}$.) is the transverse width of the two ferrite tiles. As shown in Figure 3 these tiles lie on the upper and lower surfaces of the lower leg of the coil. The quantity Q, representing the effect of the ferrite tiles in enhancing the inductance, is in the limit of high permeability of the tiles, i.e., $\mu \gg \mu_{0}$, given by the equation:

$$
\mathrm{Q}=\frac{\exp (\mathrm{ka} / 2)+\exp (-\mathrm{ka} / 2)}{\exp (\mathrm{ka} / 2)-\exp (-\mathrm{ka} / 2)}
$$

Here a (m.) is the vertical thickness of the lower leg of a coil of the array.

As can be seen from the form of equation (9), it can be rearranged to define the ratio of the added inductive loading $\mathrm{L}_{\mathrm{L}}$ (hy) to the distributed inductance, $\mathrm{L}_{\mathrm{d}}$ (hy), through the relation: 


$$
\frac{\mathrm{L}_{\mathrm{L}}}{\mathrm{L}_{\mathrm{d}}}=\frac{\mathrm{h}}{\mathrm{P}_{\mathrm{c}}}(\mathrm{Q}-1)
$$

Equations (1) through (11) may now be used to calculate the important parameters of the model Inductrack that was constructed. In these calculations we will ignore small corrections in the levitation and other parameters associated with the auxiliary Halbach arrays on each side of the car (see Figure 2). These arrays provide restoring forces for sideways motions of the car during its flight down the track.

\section{(II) Calculation of Parameters of Model}

The model Inductrack was designed on the basis of the theory outlined above. The first parameter required was the required launching speed, as this dictated the design of the mechanical launcher used in the first tests. The critical parameter here is the transition speed, $v_{t}$, defined through equation (2) and equations (8), (10), and (11). Referring to Figure 1 for the coil, the relevant parameters here include its mean perimeter, $P_{c}=0.51 \mathrm{~m}$., that it is wound with 53 turns of 150/36 litz wire (150 strands of 36 AWG copper wire), and that its thickness, $\Delta_{\mathrm{c}}=0.0125 \mathrm{~m}$. The resistance of 36 AWG wire is $1.36 \mathrm{ohms} / m e t e r$ so that the one-turn-equivalent resistance, $\mathrm{R}$, of the coil is $(1.36 \times 0.51) /(53 \times 150)=8.7 \times 10^{-5} \mathrm{ohm}$.

The one-turn-equivalent inductance of the coil, $\mathrm{L}_{\mathrm{d}}$ (i.e., before ferrite loading), can be calculated from equation (8) by inserting the values for $k$ and for $d_{c}$. From Figure 2 for the cart we see that the wavelength of the Halbach array is equal to 4 times the length of one magnet block. These magnet blocks were each .025 $\mathrm{m}$. in dimension, so that $\lambda=0.10 \mathrm{~m}$. and $\mathrm{k}=62.8 \mathrm{~m}^{-1}$. From Figure 1 we find for the mean separation distance, $d_{c}$, the value $.016 \mathrm{~m}$. Inserting these values into equation (8) we find for $L_{d}$ the value 0.63 microhenrys.

The one-turn-equivalent inductance of the coils, including the effect of the ferrite tiles, can be calculated using equations (10) and (11), by inserting $\mathrm{a}=\Delta_{\mathrm{c}}=0.0125 \mathrm{~m}$ in equation (10), and $\mathrm{h}=0.1 \mathrm{~m}$. for the width of the tiles in equation (11). We find for $Q$ the value 2.6, from which we find for the ratio of inductive loading to the 
distributed inductance the value 0.329. Thus the one-turn equivalent inductance, $\mathrm{L}=\left(\mathrm{L}_{\mathrm{L}}+\mathrm{L}_{\mathrm{d}}\right)=0.63+(0.329 \times 0.63)=0.84$ microhenrys.

The transition speed, $v_{t}=(1 / \mathrm{k})[\mathrm{R} / \mathrm{L}]$ can now be evaluated, finding $\mathrm{v}_{\mathrm{t}}=1.7 \mathrm{~m} / \mathrm{sec}$., the speed at which the lift $/ \mathrm{drag}$ ratio is 1.0 , and the lift has approached one-half of its asymptotic value. In order for the cart to fly for any substantial distance after launch, its launching speed must be considerably above this speed. In the tests we launched the cart at speeds of about 10 meters/sec. in order to have it fly in a levitated state for nearly the full length of the test track.

The next parameter to be calculated is the expected levitation height, $\mathrm{y}(\mathrm{m}$.$) , at speeds that are substantially above the transition$ speed. For this we need the mass of the cart which is 22 kilograms, and the width of the levitating Halbach arrays, $w=0.125 \mathrm{~m}$. From equation (7) for the ratio of the achieved levitating force to its maximum value we find, using the parameters already calculated:

$$
\frac{\mathrm{F}_{\mathrm{y}}}{\mathrm{F}_{\max }}=\frac{\mathrm{W}}{\mathrm{P}_{\mathrm{c}}}\left[\frac{\mathrm{L}_{\mathrm{d}}}{\mathrm{L}_{\mathrm{L}}+\mathrm{L}_{\mathrm{d}}}\right]=0.184
$$

Using this ratio and equation (6) we find for the levitating force at speeds high compared to the transition speed the expression:

$$
\frac{\mathrm{F}_{\mathrm{y}}}{\mathrm{A}}=1.1 \times 10^{5} \exp \left[-\mathrm{k}\left(2 \mathrm{y}+\Delta_{\mathrm{c}}\right)\right] \quad \text { Newtons } / \mathrm{m}^{2}
$$

Each of the levitating Halbach arrays is $0.2 \mathrm{~m}$. long and 0.125 $\mathrm{m}$. wide, so that the total levitating area of these arrays (ignoring edge effects) is $.05 \mathrm{~m}^{2}$., so that the equation for the levitating force as a function of height, $y(m$.$) becomes:$

$$
\mathrm{F}_{\mathrm{y}}=5.5 \times 10^{3} \exp \left[-\mathrm{k}\left(2 \mathrm{y}+\Delta_{\mathrm{c}}\right)\right] \quad \text { Newtons }
$$

Now inserting the required levitating force $=\mathrm{Mg}=216$ Newtons, we may solve this equation for the levitation height, y (m.), (ignoring 
small corrections from edge effects and from the effect of the sidemounted Halbach arrays). We find the value $y=0.02 \mathrm{~m}$.

The final quantity that we will calculate is the expected flight distance as a function of the launching speed and the $\mathrm{R} / \mathrm{L}$ ratio. This quantity can be evaluated by noting that the equation for the lift/drag ratio, equation (1), can be written as:

$$
\frac{\text { Lift }}{\text { Drag }}=\mathrm{Kv}, \quad \text { where } \mathrm{K}=\mathrm{k}(\mathrm{L} / \mathrm{R})=1 / \mathrm{v}_{\mathrm{t}}=0.59 \mathrm{sec} . / \mathrm{m} \text {. }
$$

Integration of the 1-D equation of motion of the cart then yields an equation for the flight distance, here defined as the distance at which the speed of the cart becomes equal to zero. In terms of its launching speed, $\mathrm{v}_{0}(\mathrm{~m} . / \mathrm{sec}$.) , the equation derived for the flight distance, $\mathrm{z}_{\max }(\mathrm{m}$.$) , is:$

$$
\mathrm{z}_{\max }=\frac{1}{3}\left[\frac{\mathrm{Kv}_{0}^{3}}{\mathrm{~g}}\right] \text { meters }
$$

At a launch speed of $10 \mathrm{~m} . / \mathrm{sec}$. this equation predicts a flight distance of about 20 meters, which is approximately the full length of the track. This result agrees roughly with the observations, which showed flight distances of order the length of the track for launching speeds of order of (slightly higher than) 10 meters/sec. The discrepancy can probably be accounted for by effects ignored in this calculation, i.e., (1) edge effects in the Halbach arrays, reducing their lift force by 10 percent or so as compared to the theory, (2) the extra drag introduced by the side-mounted Halbach arrays, and (3) aerodynamic drag (probably a small correction). In some of the tests, in particular those with the electronic drive, the launch velocity was measured at the end of the launching region, which was some meters away from the beginning of the levitating region. In these cases the speed at launch would be somewhat lower than the measured speed, owing to frictional losses in the intermediate section.

Finally, though difficult to observe, the flight heights of the cart were certainly not far from the $2 \mathrm{~cm}$. value predicted by the theory. We conclude that the theoretical formulae used to design and to predict the performance of the Inductrack model were generally 
corroborated by the experimental results. We also conclude from the analysis of the high-speed video shots of the cart in motion that, apart from transients caused at launch, the motion of the cart showed no signs of instability in flight, again in agreement with the predictions of the theory presented in reference [1].

\section{(III) Electronic Drive}

In the last phase of the investigations of the Inductrack model electronic drive circuits were introduced at the beginning of the track. These circuits were employed to accelerate the cart to launch speeds. Within the time and funding limitations it was not possible to complete the full complement of circuits, but with a starting assist from stretched "bungee" cords launching speeds in excess of 10 meters per second were achieved, resulting in stable flights over nearly the full length of the test track.

In the electronic drive a set of 45 coils of the same type as the levitating coils were mounted in a spaced array (spacing $0.1 \mathrm{~m}$.) that was $4.5 \mathrm{~m}$. long, located just before the beginning of the levitating track. These coils were energized by half-sine-wave pulses derived from the discharge of electrolytic condensers (operating voltage = 400 V., total capacity $=3600 \mathrm{mfd}$.) through silicon-controlledrectifiers (SCRs). Figure 4 is a photograph of two of the pulse-driver modules with their electrolytic condensers and SCRs and protective diodes mounted on the assembly.

The SCRs were triggered by impulses from small microswitches spaced along the track at the position of the drive coils. These switches were activated by a mechanical "paddle" carried on the cart itself, thus guaranteeing synchronization of the drive-current pulses with the position of the cart, in particular, with the vertical field component produced by the front Halbach array at a position halfway back from its front edge.

The peak currents from the drive circuits were of order 400 amperes, and the pulse durations produced by the circuits were of order 3 to $5 \mathrm{~ms}$. (depending on position down the track; shorter near the far end). Since the coils that were used had 53 turns, the effective transverse current, seen by the Halbach arrays and producing the drive impulses, was about 20,000 amperes. This current then produced an impulsive force, the peak value of which 
can be estimated from the calculated peak strength of the magnetic field at the position of the drive coil given by the relationship:

$$
\mathrm{B}_{\mathrm{y}}=\mathrm{B}_{0} \quad \exp \left[-\mathrm{k}\left(\mathrm{y}+\Delta_{\mathrm{c}} / 2\right)\right] \quad \text { Tesla }
$$

Here $\left(\mathrm{y}+\Delta_{\mathrm{c}} / 2\right)$ is approximately $.025 \mathrm{~m}$. The peak force then is given by:

$$
\begin{gathered}
\mathrm{F}_{\mathrm{z}}(\max )=\mathrm{B}_{\mathrm{y}} \text { w } \mathrm{I}=[(0.713)(1.23)][\exp (-62.8 \times .0 .025)][0.125]\left[2 \times 10^{4}\right] \\
=4.6 \times 10^{2} \quad \text { Newtons }
\end{gathered}
$$

Thus the peak instantaneous value of the "g" acceleration of the cart while passing over a coil of the electronic drive is approximately (4.6 $\left.\mathrm{x} 10^{2}\right) /(22 \mathrm{x} 9.8)=2.1 \mathrm{~g}$. The average "g" value was, of course, smaller, corresponding to a value of about $1.1 \mathrm{~g}$, as estimated from the length of the electronic-drive portion of the track and the achieved launching velocities.

\section{(IV) Conclusion}

We have designed, constructed, and operated a model Inductrack passive magnetic levitation system. The design was based on a theoretical analysis which predicts the levitation forces and the lift-to-drag ratios for such systems. As also predicted by the theory the levitated motion was found to be stable. Reasonable agreement was also found between the experimental results and the theory for the levitation height and the flight distances for the levitated cart, giving confidence in the validity of the theory for extrapolation to larger-scale systems.

\section{(V) Acknowledgements}

The considerable assistance of Dmitri Ryutov in the theoretical analysis, of J. Ray Smith in designing the gravity-drive system and in overseeing the operation of the model, of Edward Cook in the design of the electronic circuits, and of William Kent in constructing, assembling, and operating the Inductrack model is gratefully acknowledged. 


\section{References}

[1] R. F. Post, D. D. Ryutov, "The Inductrack Concept: a New Approach to Magnetic Levitation," Report UCRL-ID-124115, May 1996

[2] K. Halbach, "Application of Permanent Magnets in Accelerators and Electron Storage Rings," Journal of Applied Physics, 57, 3605 (1985)

[3] D. D. Ryutov (private communication)

\section{Figure Captions}

Figure 1: Drawing of a typical levitating coil and a cross-section of the windings showing the number of turns and type of wire.

Figure 2: Front-view photograph of the cart and the track coil assembly. The cart is shown at its approximate height of levitation in flight above the track.

Figure 3: Schematic drawing of a cross-section of the track coil assembly showing the location of the ferrite tiles used for inductive loading.

Figure 4: Photograph of two of the electronic drive modules used to launch the cart down the track 
Inductrack Model Coil
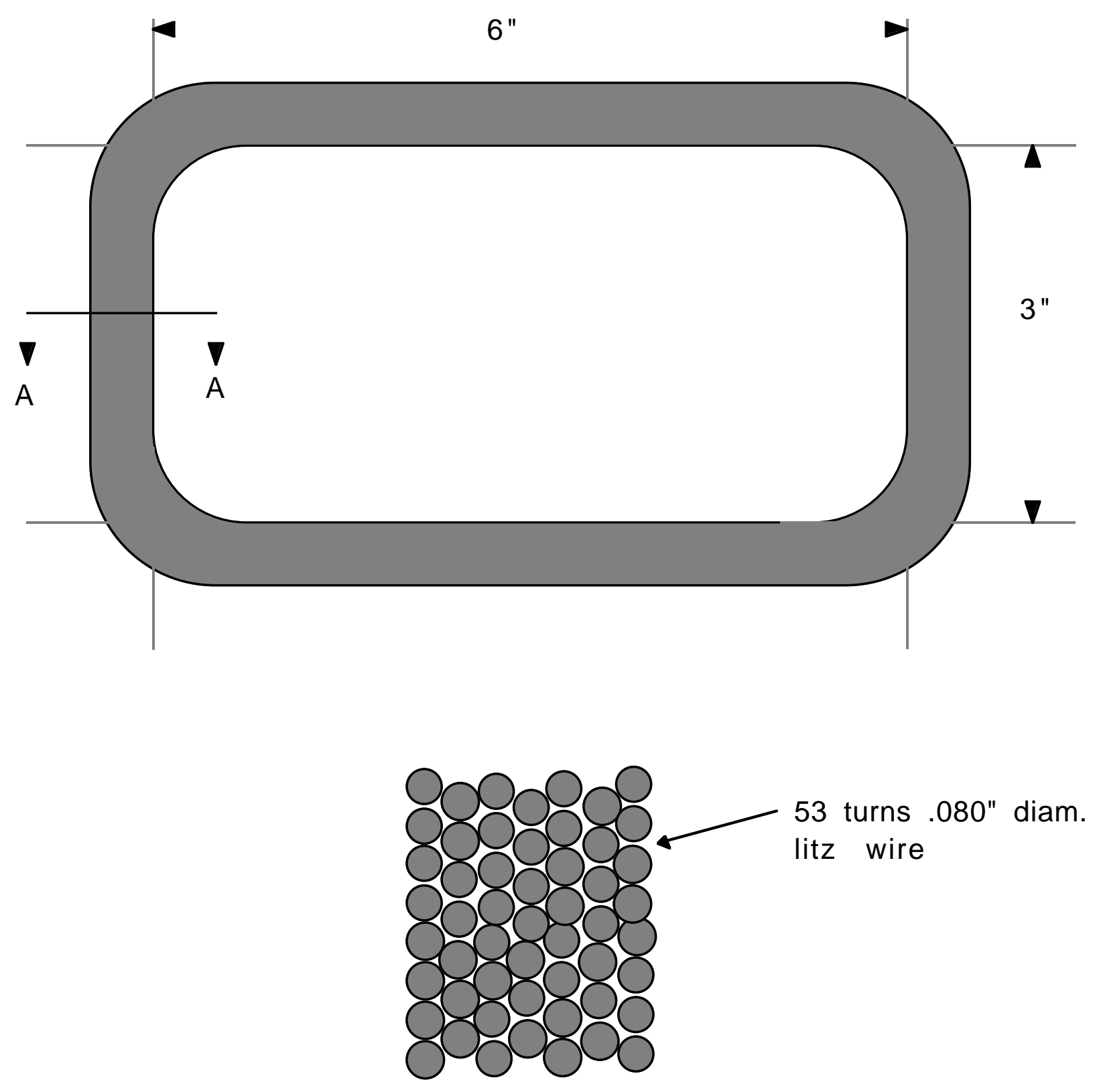

Section A-A (not to scale)

Figure 1 


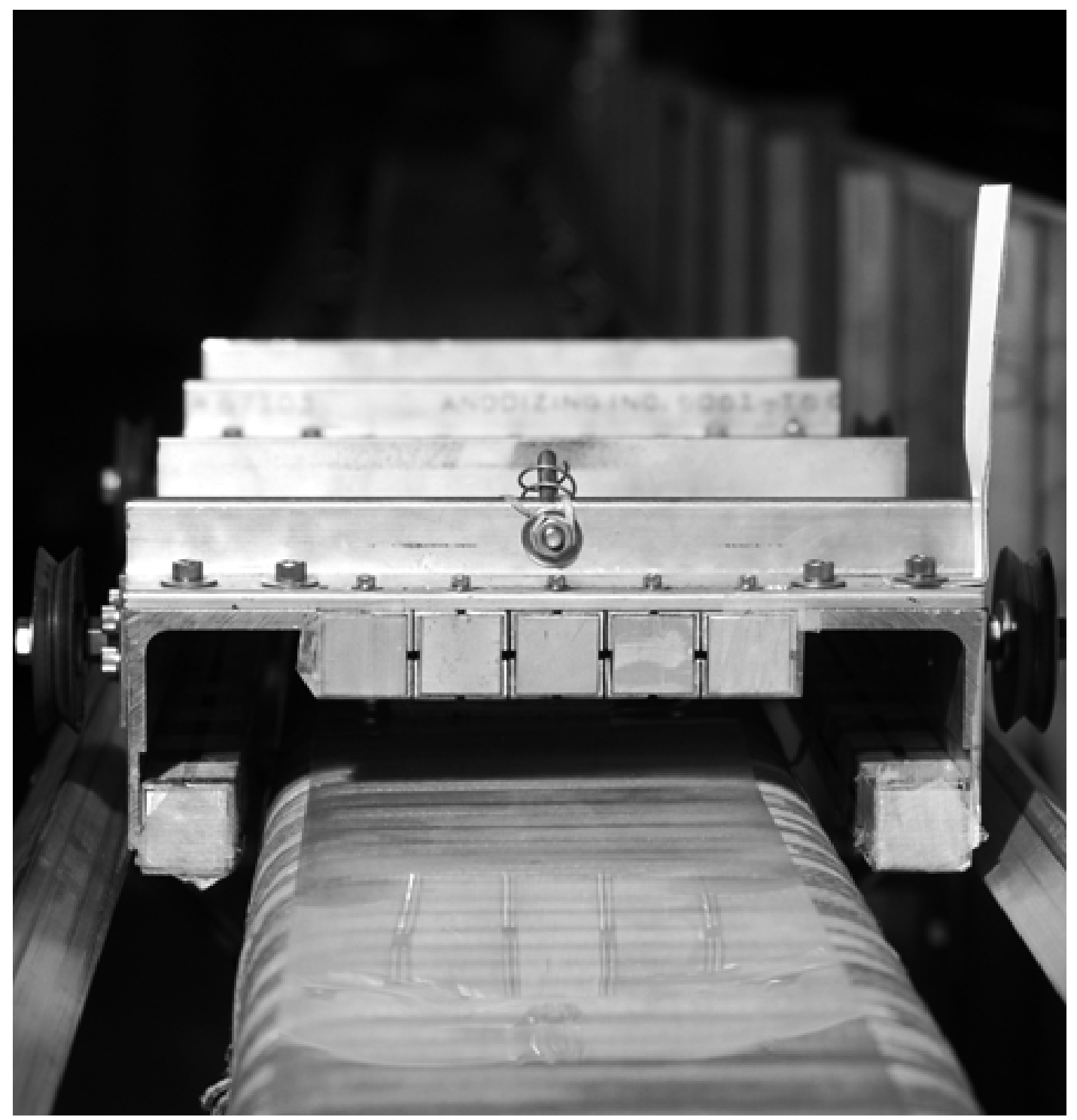

Figure 2 


\section{Schematic Drawing of Inductrack Model Track}

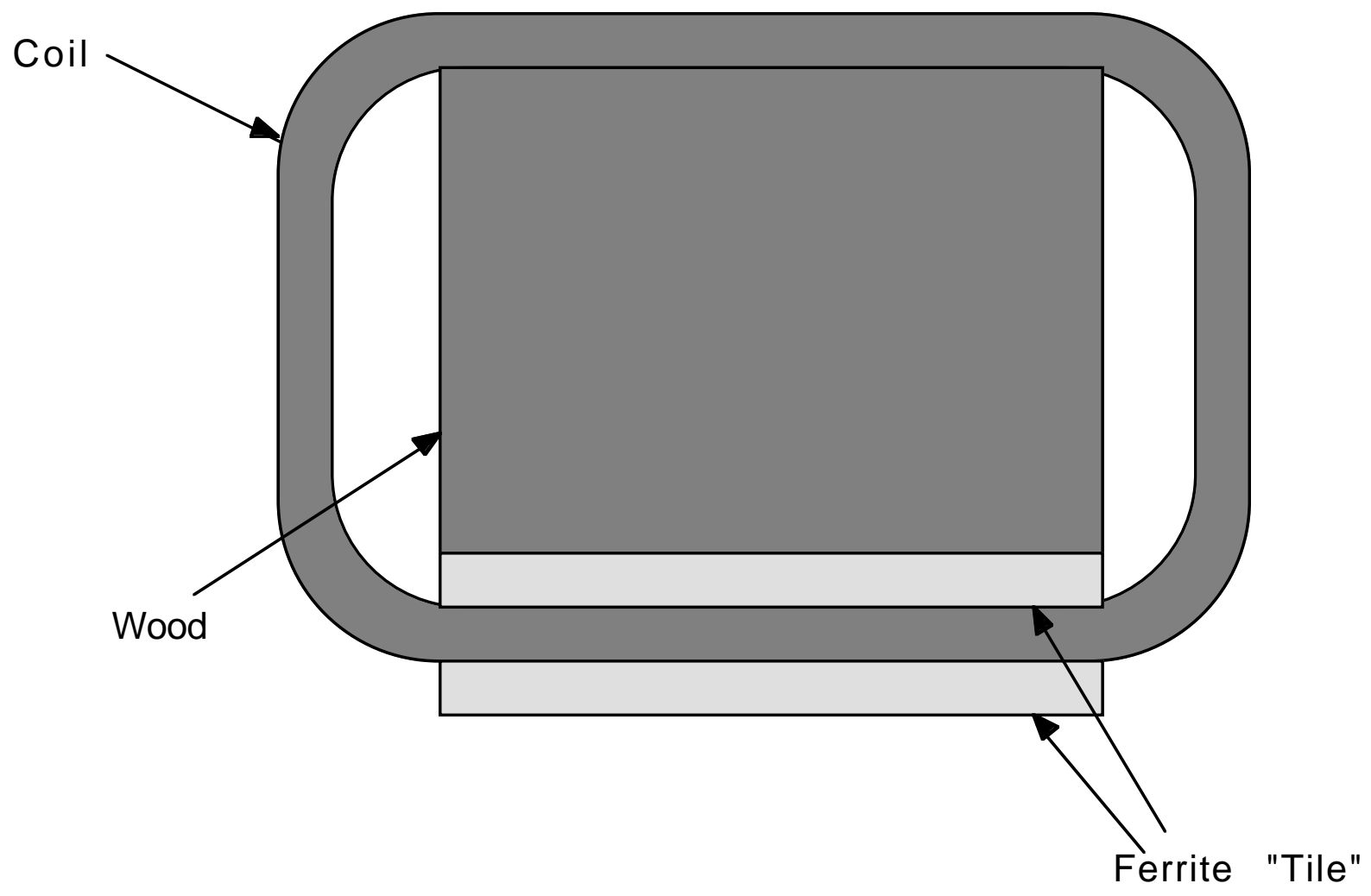

Figure 3 


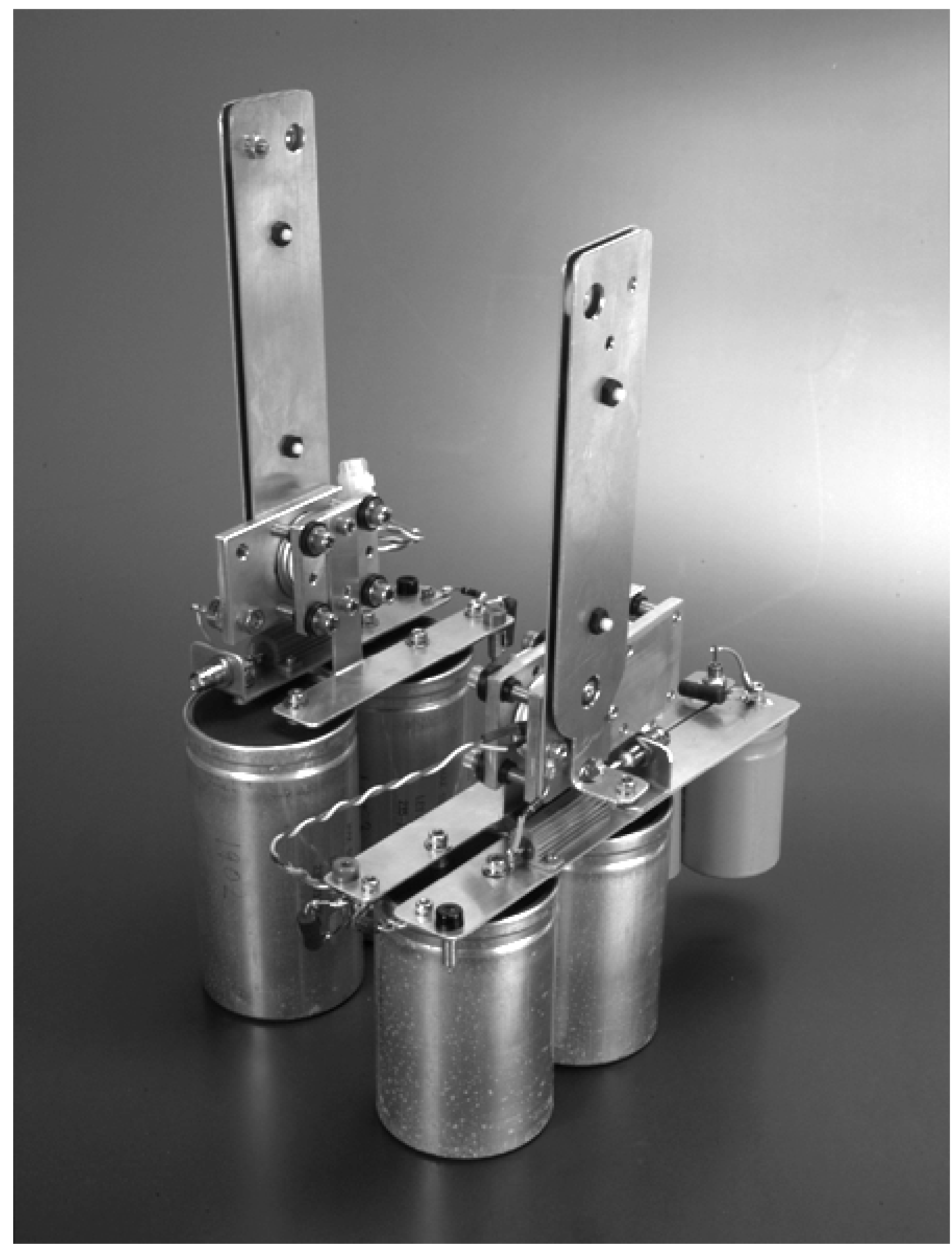

Figure 4 


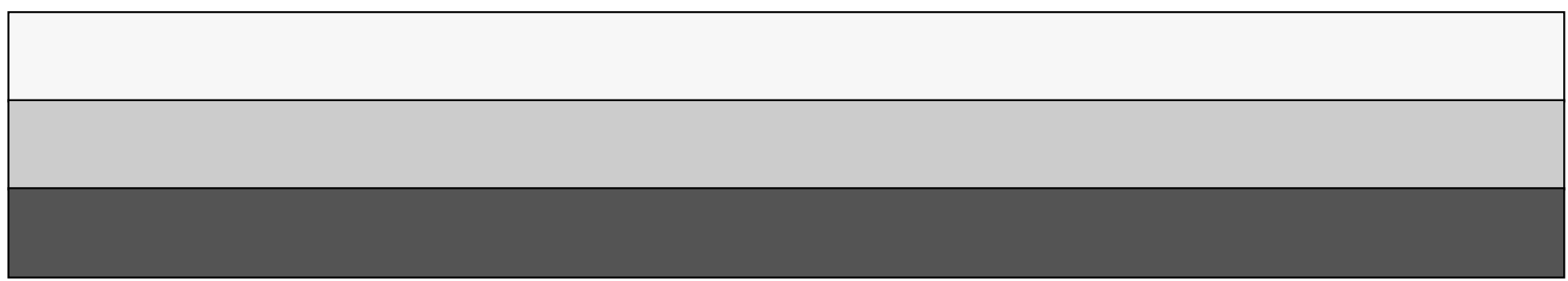

